THURSDAY, AUGUST 25, 1870

\section{SCIENCE AND MILITARY SURGERY}

$\mathrm{T} \mathrm{T}$ is matter of no small interest at the present time to know something of the scientific position of our Army Medical Service. The question has two aspects-first, the purely professional and technical ; and second, the general and scientific. In former times sick and wounded soldiers in all services had inadequate care bestowed on them, but for many years past the advance of humane principles, and improvements in education and in all manner of appliances, have been gradually making way in different European armies ; and at this time we are presented with the astonishing spectacle of distinct corps of men and women, many of them of noble and gentle birth, following the example first set by Florence Nightiringale, leaving their families and homes to accompany armed hosts to the battle field-their lives considered sacred by both sides - with the single object of conveying away poor wounded men as speedily as possible to shelter and to surgical and nursing care.

It would not be difficult to trace this great movement to the disasters of the British army during the Crimean war ; an 1 to the same event we have been indebted for the striking scientific advance in our own army medical service. We have been led into making these remarks by a perusal of the Army Medical Department Report for I868. This is the tenth volume of an interesting series of official documents, the commencement of which dates from the reforms introduced by the late Lord Herbert.

The present volume maintains the reputation already gained by its predecessors, and even for non-professional readers it affords information of much general interest. A brief sketch of its contents will be sufficient for the object we have in view.

In turning over its pages we find in the first place the medical statistics of the whole British army. Wherever Her Majesty's troops are stationed, there the statistical officer is at work collecting and registering facts, which show not only the state of health at each station, but the diseases incidental to countries and climates the most diverse.

The death rates, which for foreign stations includo deaths among invalids, show a large reduction over those which ruled in former years, but in many cases they are considerably too high, and indicate the necessity for increased sanitary precautions. The greatest reductions liave been effected in India, where for the first half of the present century the rates averaged no less than 69 per 1000. In 1868 the death-rate was $21^{\circ} 7$ per 1000.

The reports from stations are accompanied by sanitury notes, in which the reasons for these death rates are more or less discussed, and there are valuabie reduction tables showing the influence of age, locality, \&c., on the rates.

The net results of the Abyssinian expedition are given as follows:- The aggregate strength of British troops sent to Abyssinia at various dates was 4,208 . There were 42 deaths in Abyssinia, and 12 among invalids in England, making 54 in all ; equal to 12.8 per 1000 . There were 12 admissions but no deaths from wounds. The total loss arose from disease and accident, the latter cause occasioning 14 deaths.
Among the scientific papers is one by Dr. Wright, giving an account of experiments on the ventilation of $a$ barrack-room, and affording an insight into the nature of solid particles floating in impure air, which particles formed the subject of Prof. Tyndall's lecture on "Dust and Disease," at the Royal Institution, last spring.

The presence of dust particles in the dir of the Royal Institution was shown by their reffecting a strong light thrown on them. In Dr. Wright's experinents made at Netley Hospital, 26 cubic feet of air were drawin through an aspirator, and the suspended matters in this air were condensed, and gave the following results under a $\frac{1}{8}$ th inch object"glass :-

Cotton fibres.

Starch granules.

Crystalline substances, sand, or dust.

Vegetable tissues of various sorts.

Pollen.

Amorphous Molecules (? Detritus of epithelium).

Indefinite filaments.

Minute moving particles (? Zoospores).

It is important to point out that these substances were detected in the air of a sleeping-room occupied by $1 \mathbf{I}$ men, where each man had 828 cubic feet of air space, the air of which was renewed upwards of four times cvery hour. The carbonic acid ratio in the outer air was 393 per 1000 volumes, and in the room air, 643 per 1000 volumes. The practical result being that for some reason the actual ventilation of the room was very defective, although the quantity of air ought to have been more than sufficient.

Dr. Parkes has supplied an interesting paper on Dr. Hassall's Flour of Meat, giving an experimental account of its effect as a diet on two healthy persons. The object vas to ascertain whether it could be used by soldiers, and to what extent. The results arrived at are what might have been expected, viz., that nitrogenous foods of this class are, by themselves, insufficient for purposes of health and nutrition; while, as Dr. Parkes tells us, "the effect on each gentleman of the addition of other articles of diet (vegetables, fat, and a little more starchy food) was described by both as perfectly marvellous." This result gives the clue to the proper manner of using prepared foods of this class.

Dr. Parkes likewise furnishes a report on the progress of hygiène for the year 1869 , in which a useful digest is given of the leading contributions made to this important subject in various countries. One important scientific result of painstaking inquiries into the relation of cattle diseases to specific fungi, carried out in America, is stated as follows:- "It will thus be seen that the authors trace all the forms of fungi seen in the blood and fluids in the pleuro-pneumonia, or splenic disease of cattle, to common forms, and that they entirely differ from Hallier on this point."

Hallier has fared no better with his theory of specific cholera fungi at the hands of Drs. Lewis and Cunning-

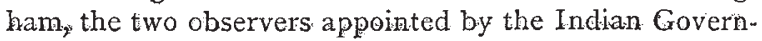
ment to examine into the question in India. These gentlemen furnish a paper on this subject, in which they state that up to the time of report the fungi supposed to be peculiar to cholera belong to common forms.

There is a curious paper by Dr. Smith on the notorious Delhi boil, in which he goes a long way in cornecting 
this disease with impure water used for ablution purposes by the troops. He shows that dogs who drink this water get boils on their noses, while human beings are affected at the points where the skin is rubbed in the process of ablution. Microscopic preparations of the boil appear to show the presence of ova of distomata similar to those detected long ago in London waters by Dr. Hassal.

Professor Longmore furnishes some valuable remarks on the Prussian arrangements now in actual operation for transport of wounded in time of war. These remarks have a special interest at the present time, and they are illustrated by Professor Longmore's own personal experience. Ordinary railway-carriages and goods-waggons have been selected by the Prussians for the conveyance of wounded by rail. In ordinary fourth-class carriages hooks are screwed into the opposite sides of the carriage, and the field-stretchers with wounded are carried inside and suspended by elastic rings on the hooks. The operation is facilitated by the lower class carriages having a door at each end. When goods-waggons are used, the stretchers are either suspended or, which is far better, they are placed on poles laid on semi-elliptical steel springs inserted in the floor of the waggon. Professor Longmore prefers the arrangements in the fourth-class carriages, as being easier in practice.

There is in the Prussian army a complete organisation of medical officers, bearers, stretchers, field ambulances, $\& c$, for collecting the wounded, dressing them on the spot, and conveying them either to the railway or to hospital, where, as we are glad to learn, they are now meeting with every care and kindness at the hands of humane men and women, whose motto may well be that adopted by one of the societies-" Point d'ennemis pour nous." * After describing the exercises he witnessed, Professor Longmore very properly suggests whether we in this country might not do something in the way of organising a suitable ambulance corps? This was one of Lord Herbert's proposed reforms, but we are afraid little has been done in giving effect to it.

Another subject discussed is the method adopted for identifying the bodies of the killed by means of tickets attached to the clothes or worn round the neck.

There are several other papers, including monthly meteorological abstracts for stations scattered over the whole British Empire, which we should have gladly noticed had our space permitted. But we have said enough to show that, in scientific advantages, the Army Medical Department, with its efficient school at Netley, stands second to none in Europe. It is for those who have the direction of the army to see that there is an organisation provided to give practical effect to it in the field where its services are most required.

\section{THE ANNUAL REPORT OF THE ROYAL}

$$
\text { COLLEGE OF SURGEONS }
$$

H OR some years past it has been a custom at the College of Surgeons for the Conservator to collect the various specimens that have been mounted during the preceding twelve months into one room; enabling not only the Museum Committee, but the members of the medical pro-

* Contributions in aid of this great work may be sent to the National Society for the Aid of Sick and Wounded, 2, St. Martin's Place, Trafalgar Square, S.W. fession, or visitors introduced by them, to see at a glance the additions that have been made during that period. We consider the plan to be an excellent one. It is a powerful incentive to the Conservator to work so that each year's results may surpass the previous one ; whilst it calls forth gifts from those who have the opportunity of obtaining rare or valuable specimens, when they see what loving care and diligence are spent on their preparation and exhibition, and to how large a number they afford instruction. We had recently an opportunity of minutely inspecting these additions, and must express our warm admiration at their number and beauty. The Museum, as every naturalist knows, was commenced by the genius of Hunter, who, recognising the value that would attend the comparison of the same organ in the different groups of animals in enabling us to acquire precise knowledge of its function, and to penetrate the mysteries of disease, collected from all quarters typical specimens which he carefully dissected and described; but worker as he was the preparations he left have constituted but landmarks for the direction of succeeding observers. Although neither his time, strength, nor opportunity permitted that he should bring home more than a few examples displaying the wondrous fertility of the new region he had discovered, his success stimulated others to do their utmost. Preparation after preparation of every organised being that could be obtained by purchase or gift was rapidly added, and many times it has been found necessary to enlarge the receptacle for the sake of the new and important preparations that had been obtained, till at length it has attained its present lordly dimensions, and stands without a rival in the world. Nothing, perhaps, could give such an idea of the vast increase it has undergone -which would surely have well pleased its founder, could he have seen how his small though valuable beginnings had increased and multiplied-as the fact that a roomful of preparations that would handsomely furnish forth an entire country museum, is year by year absorbed into it, and scarcely appreciably augments its size.

The additions are divided into six classes-I, The Pathological Collection; 2, The Osteological ; 3, The Physiological; 4, The Teratological; 5, The Dermatological ; and 6, Anatomical preparations. The first of these has received many additions, and in particular one very important one, in which the carotid and subclavian arteries were tied by Mr. C. Heath for aneurism, and in which life was preserved for four years, and would probably have been considerably prolonged but for the extremely unsteady habits of the patient. The duration of life after the operation has permitted the collateral circulation to be fully established, and all the parts have been beautifully dissected out by Mr. Mosely.

In regard to the osteological collection, a large collection of ancient and modern Italian and Greek skulls has been purchased from the well-known Italian ethnologist, Dr. G. Nicolucci, of Isola di Sora. The number of these skulls was 166 , and the entire number in the museum now amounts to 795 , the great proportion of them being well authenticated and characteristic examples.

It is one thing, however, to have fine specimens, and another to display them to the best advantage; and often the chief value of a specimen, or even of a collection, is spoiled by the slovenly manner in which the mounting is effected, 